\title{
On the gestation period of Indian pangolins (Manis crassicaudata) in captivity
}

\section{Short communication}

Indian pangolin (Manis crassicaudata Gray, 1827) is one of the eight living species of pangolins in the world. They are toothless, nocturnal, burrowing, myrmecophagous mammals and occur throughout peninsular India, Sri Lanka, Bangladesh and Pakistan. Indian pangolins, like all other pangolin species, do not breed readily in captivity. Although births have been reported throughout the year except for May and June, observations on the gestation period of Indian pangolins are limited as mating and subsequent births are seldom observed. ${ }^{1-10}$ The present communication is based on one observation on the mating and gestation period of Indian pangolin. We observed mating on 25-02-2014 between an adult female Indian pangolin (Microchip ID-00074D5A63, weighing $8.5 \mathrm{~kg}$ ) and an adult male Indian pangolin (Microchip ID-98102058378, weighing $9.3 \mathrm{~kg}$ ) at Pangolin Conservation Breeding Center, Nandankanan Zoological Park, Odisha, India. The detailed observation on the mating behavior was described elsewhere. ${ }^{11}$ The same female was separated and housed alone thereafter and gave birth to a baby pangolin on 03-112014. In the present case, the gestation period was 251 days. We are reasonably confident about the accuracy of the gestation period during the present study, as, after observation of one-time mating event on 25-02-2014, the pair was separated and the female was individually housed until the 03-11-2014 when we observed a baby pangolin
Volume 2 Issue 6 - 2018

\author{
Rajesh K Mohapatra,' Sudarsan Panda, ${ }^{2}$ Sarat \\ K Sahu' \\ 'Nandankanan Zoological Park, India \\ ${ }^{2}$ RCCF Angul, India
}

Correspondence: Rajesh Kumar Mohapatra, Nandankanan Zoological Park, Odisha, India, Tel +9199 3756 3742, Email rajesh.wilblife@gmail.com

Received: October 17,2018| Published: November 23, 2018

attempting to crawl over the mother pangolin inside a burrow, with the umbilical cord still attached and watery discharge on mother's hind legs, as a sign of recent birth (Figure). The pangolin baby measured $25 \mathrm{~cm}$ nose tip to tail tip with a $10.5 \mathrm{~cm}$ tail and weighed $160 \mathrm{~g}$. The baby was pinkish in color and with soft scales. Tiny hairs were present on the ventral surface of the body whereas long hairs were present on the dorsolaterial sides protruding beyond the scales. Eyes of the baby were closed at birth. The external genitalia of the baby appeared prominent and possible to sex it as male on the very day of birth (Figure 1).

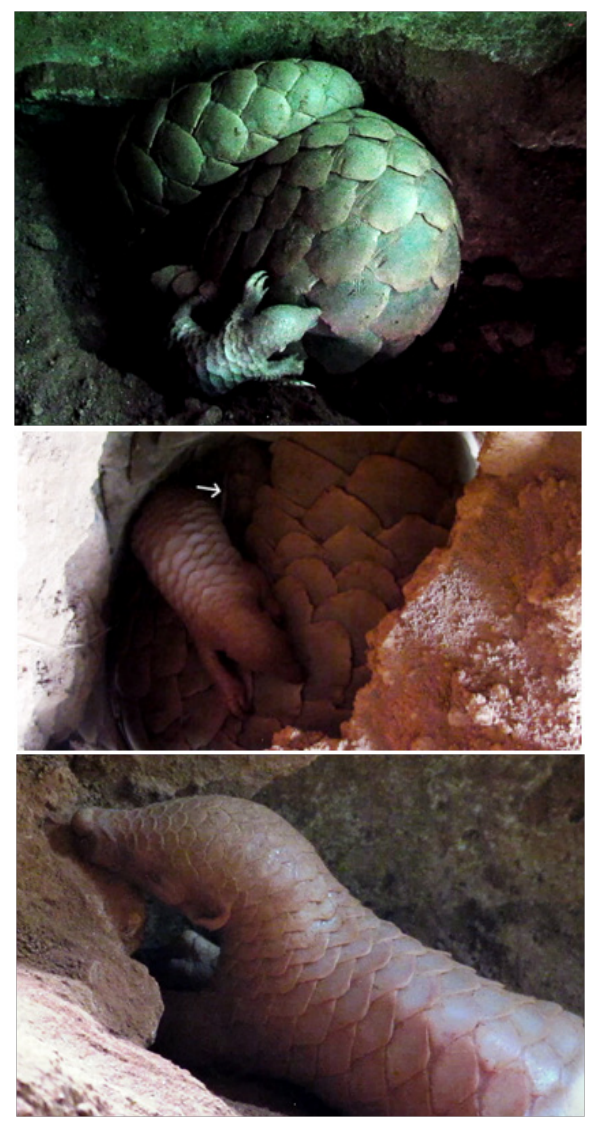

Figure I Top to bottom; Pangolin baby with mother, umbilical cord between mother and baby, eyes of the baby not open at birth. 
Acharjyo \& Misra $^{4}$ reported the litter size as one and the baby pangolin weighed $235 \mathrm{~g}$ and measured $30 \mathrm{~cm}$ in total body length including $12.5 \mathrm{~cm}$ long tail at birth. They also reported that eyes of the pangolin baby are open at birth. But in the present case the authors have recorded a birth with eyes closed. So it can be said that pangolin babies are born with their eyes closed or open. Mahmood et al., ${ }^{11}$ reported on the basis of questionnaire survey undertaken in Potohar plateau of Pakistan reported that, Indian pangolins breed once a year, usually twins were born between July \& October and juvenile pangolins observed during the month of January. Roberts ${ }^{7}$ stated that Indian pangolin has a litter of one offspring, a gestation period of more than 80 days, and that the species gives birth in November.

\section{Acknowledgements}

None.

\section{Conflict of interest}

Author declares that there is no conflict of interest.

\section{References}

1. Phillips WWA. A note on the habits of the Indian pangolin (Manis crassicaudata). Spolia zeylanica. 1928;14:333.

2. Prakash I. Breeding of mammals in Rajasthan desert, India. Journal of Mammology. 1960;41(3):386-389.
3. Ogilvie PW, Bridgwater DD. Notes on breeding of an Indian pangolin at Oklahoma Zoo. International Zoo Year Book. 1967;7:116-118.

4. Acharjyo LN, Misra R. Birth of Indian pangolin (Manis crassicaudata) in captivity. Journal of the Bombay Natural History Society. 1972;69(1):174-175.

5. Acharjyo LN, Mohapatra S. A note on breeding and longevity of Indian pangolin (Manis crassicaudata) in captivity. Journal of the Bombay Natural History Society. 1978;75(3):921-922.

6. Hoyt RA. Pangolins: past, present and future. AAZPA Conf Proc. 1987;107-134.

7. Roberts TJ. The Mammals of Pakistan. $2^{\text {nd }}$ edn. Pakistan: Oxford University Press; 1997. p. 131-135.

8. Prater SH. The Book of Indian Animals. $3^{\text {rd }}$ edn. Mumbai: Bombay Natural History Society; 2005. p. 301-303.

9. Mohapatra RK, Panda S. Husbandry, behaviour and conservation breeding of Indian pangolin. Folia Zoologica. 2014;63(2):73-80.

10. Mahmood T, Irshad N, Hussain R, et al. Breeding habits of the Indian pangolin (Manis crassicaudata) in Potohar Plateau, Pakistan. Mammalia. 2016;80(2):231-234.

11. Mohapatra RK, Panda S, Nair MV. On mating behaviour of captive Indian pangolin (Manis crassicaudata). Taprobanica. 2015;7(1):5759. 